\title{
All-silicon photovoltaic detectors with deep ultraviolet selectivity
}

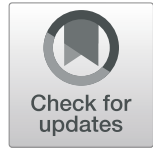

Yuqiang Li, Wei Zheng ${ }^{*}$ (D) and Feng Huang

\author{
* Correspondence: zhengw37@mail. \\ sysu.edu.cn \\ State key Laboratory of \\ Optoelectronic Materials and \\ Technologies, School of Materials, \\ Sun Yat-sen University, Guangzhou \\ 510275, P. R. China
}

\begin{abstract}
For a practical photodetector, fast switching speed and high on-off ratio are essential, and more importantly, the integration capability of the device finally determines its application level. In this work, the judiciously engineered $\mathrm{Si}_{3} \mathrm{~N}_{4} / \mathrm{Si}$ detector with an open-circuit voltage of $0.41 \mathrm{~V}$ is fabricated by chemical vapor deposition methods, and exhibits good performance with repeatability. The advanced integration technology of $\mathrm{Si}_{3} \mathrm{~N}_{4}$ and $\mathrm{Si}$ is the foundation for imaging functions in the near future. Compare to the current commercial Si p-i-n photodiodes, the detector cuts off the long-wavelength UV light over $260 \mathrm{~nm}$, realizing the spectrum selectivity without filters or complexed accessories. The stability of this detector is further characterized by cycling response, temperature and light intensity dependence tests. In addition, we also analyze and explain the inherent mechanisms that govern the different operations of two types of $\mathrm{Si}_{3} \mathrm{~N}_{4} / \mathrm{Si}$ photodetectors.
\end{abstract}

Keywords: Photodetection, Silicon nitride, Photovoltaic, Deep ultraviolet, Silicon based

\section{Introduction}

High-performance photodetectors with integration potential for imaging are desired in deep ultraviolet (DUV) detection, such as space communication, solar storm observation and atmosphere monitoring [1-3]. Silicon as the most important semiconductor, its photodetection imaging has been demonstrated in the visible and infrared bands, benefiting from its completed growth and processing technology [4, 5]. However, the direct use of silicon in ultraviolet field is prevented by its narrow band gap. The lack of specific absorption for UV light makes silicon inevitably affected by visible and infrared light, curtailing the spectrum selectivity. Attaching a filtering apparatus leads to more complexity, low integration and poor portability of detectors [6]. An important trend in photodetection is to combine DUV sensing materials with silicon readout circuits, enabling working at $0 \mathrm{~V}$ bias (photovoltaic), faster response speed and more complicated on-chip signal-processing functions [7].

In current, oxides and nitrides are the materials mainly used for DUV detection $(<$ $280 \mathrm{~nm}$ ) [8-12]. The oxides usually mismatch with silicon, and $\mathrm{SiO}_{2}$ interlayers or other compounds generate easily during the growth, which may block carrier transport

(c) The Author(s). 2020 Open Access This article is licensed under a Creative Commons Attribution 4.0 International License, which permits use, sharing, adaptation, distribution and reproduction in any medium or format, as long as you give appropriate credit to the original author(s) and the source, provide a link to the Creative Commons licence, and indicate if changes were made. The images or other third party material in this article are included in the article's Creative Commons licence, unless indicated otherwise in a credit line to the material. If material is not included in the article's Creative Commons licence and your intended use is not permitted by statutory regulation or exceeds the permitted use, you will need to obtain permission directly from the copyright holder. To view a copy of this licence, visit http://creativecommons.org/licenses/by/4.0/. 
and weaken the built-in electric field. Unfortunately, $\mathrm{SiO}_{2}$ itself cannot be used as a proper DUV detection material due to its too large band gap [13]. AlN and BN preparation conditions are too harsh, with etching and integration technologies in their infancy, which leaves a long way from the imaging capabilities of their devices [14-16]. The lack of suitable materials results in DUV photodetection not being used as widely as infrared ones [17].

Based on a large amount of data and meticulous analysis, we realize that $\mathrm{Si}_{3} \mathrm{~N}_{4}$ as a proper wide band gap material has been neglected. It has a very high level of integration with $\mathrm{Si}$ [18]. $\mathrm{Si}_{3} \mathrm{~N}_{4}$ is usually used as a dielectric or passivation layer, but it also possesses the band gap greater than $5.2 \mathrm{eV}$ and a mature growing-processing technology $[19,20]$. Taking $\mathrm{Si}_{3} \mathrm{~N}_{4}$ as a photosensitive layer combined with $\mathrm{Si}$ may be an excellent way to achieve practical DUV photodetector.

In this work, amorphous $\mathrm{Si}_{3} \mathrm{~N}_{4}$ is prepared on $\mathrm{Si}$ by low-pressure chemical vapor deposition (LPCVD) and inductively coupled plasma chemical vapor deposition (ICPCVD) methods. The grown $\mathrm{Si}_{3} \mathrm{~N}_{4}$ film has a flat surface, pure composition, and appropriate band gap $(5.8 \mathrm{eV}) . \mathrm{Si}_{3} \mathrm{~N}_{4} / \mathrm{Si}$ composite photodetector was further fabricated, which has a photogenerated voltage of $0.41 \mathrm{~V}$ and an ultra-fast temporal switching speed. In addition, the detector exhibits a good absorption cut-off edge for incident light. Compared to commercial $\mathrm{Si} \mathrm{p-i-n} \mathrm{photodiodes,} \mathrm{it} \mathrm{has} \mathrm{no} \mathrm{response} \mathrm{to} \mathrm{long-wave}$ UV, fulfilling DUV selectivity. Other systematic characterizations of the device, including switching cycling, temperature dependence and illumination intensity dependence, all indicate a reliable and practical detector.

The switching speeds of the photodetectors consist of LPCVD- $\mathrm{Si}_{3} \mathrm{~N}_{4}$ or ICPCVD$\mathrm{Si}_{3} \mathrm{~N}_{4}$ are distinct under slow response, but tend to be consistent under temporal response. The difference of switching speed is speculated to originate from deep-level defects in the materials, by analyzing the atomic-level morphology and element distribution of the $\mathrm{Si}_{3} \mathrm{~N}_{4} / \mathrm{Si}$ interface. The experiments and analysis may provide reference for the construction of other high-performance $\mathrm{Si}_{3} \mathrm{~N}_{4}$ detectors. In brief, this research broadens the using fields of $\mathrm{Si}_{3} \mathrm{~N}_{4}$ in photonics, and more importantly, paves the way for the application of DUV photodetection.

\section{Results and discussion}

Fifty nanometer amorphous $\mathrm{Si}_{3} \mathrm{~N}_{4}$ film is prepared on the $\mathrm{n}$-Si surface by LPCVD method at $1200^{\circ} \mathrm{C}$, in which nitrogen penetrates into the interior of $\mathrm{Si}$ and react with it. A series of characterizations for the $\mathrm{Si}_{3} \mathrm{~N}_{4}$ film are implemented. The cross-sectional scanning electron microscope (SEM) morphology of $\mathrm{Si}_{3} \mathrm{~N}_{4}$ is shown in Fig. 1b, revealing a clear and straight interface, which is further reflected in high-resolution transmission electron microscope (HRTEM) image (Fig. 1c). Atomic force microscope (AFM) results show that the $\mathrm{Si}_{3} \mathrm{~N}_{4}$ film has an ultra-flat surface with root mean square of roughness only $0.76 \mathrm{~nm}$, advantageous for establishing high-performance detectors [21, 22]. Through further analysis of energy dispersive spectroscopy (EDS) mapping and X-ray spectroscopy (XPS), it can be confirmed that the element distribution of $\mathrm{Si}_{3} \mathrm{~N}_{4}$ is quite uniform, and the $\mathrm{N}, \mathrm{Si}$ elements are in the accurate valence state. The peak positions of $\mathrm{N}_{1 \mathrm{~s}}$ and $\mathrm{Si}_{2 \mathrm{p}}$ are located at $397.63 \mathrm{eV}$ and $101.88 \mathrm{eV}$ respectively [23]. The absorption spectrum of Fourier transform infrared (FTIR) spectroscopy also proved that in this $\mathrm{Si}_{3} \mathrm{~N}_{4}$, only the 


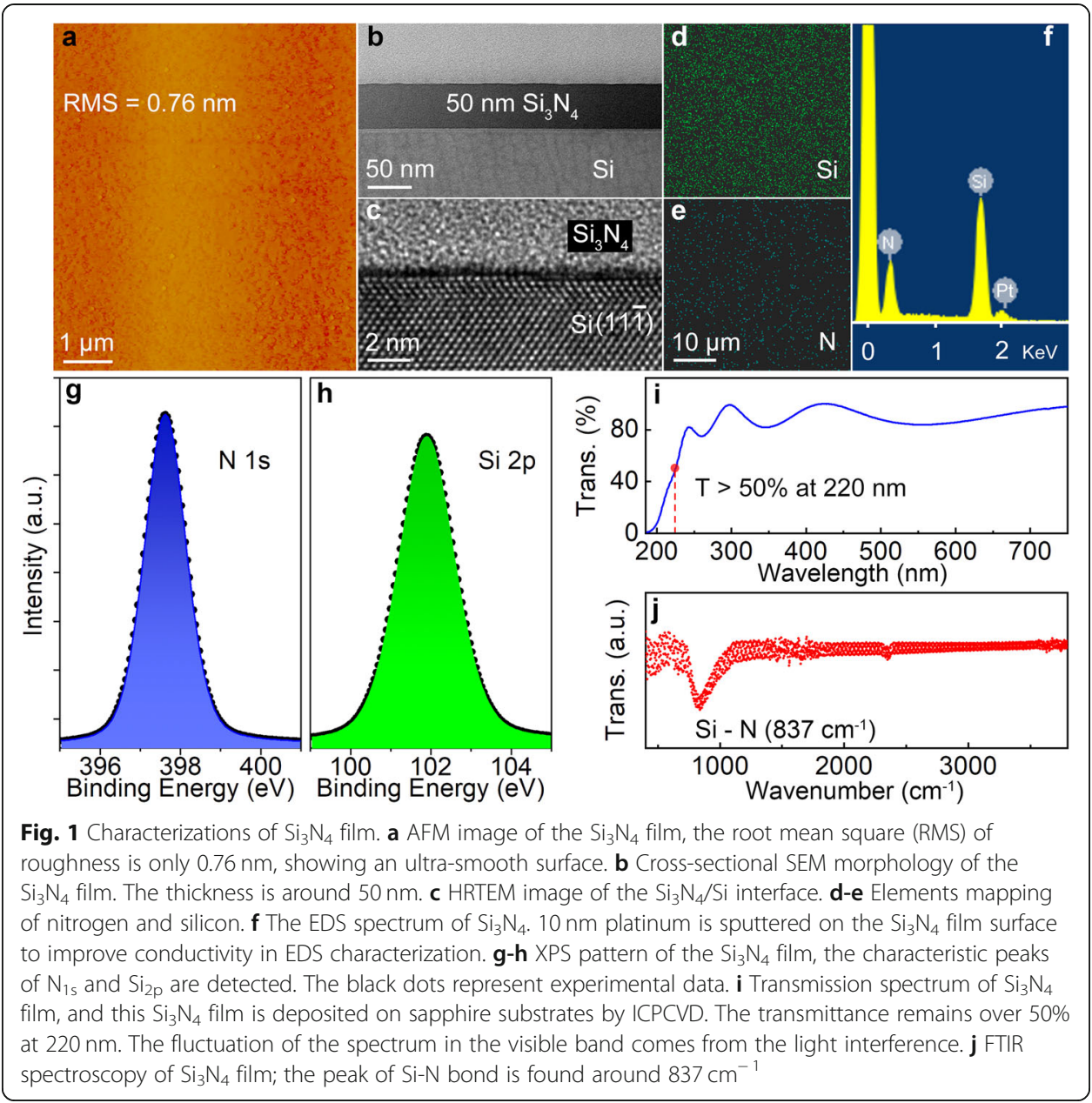

vibration of $\mathrm{Si}-\mathrm{N}$ bond exists, which reflects the high purity of the film [24]. The band gap of the grown $\mathrm{Si}_{3} \mathrm{~N}_{4}$ is estimated to be around $5.8 \mathrm{eV}$ by UV-visible transmission and absorption spectrum, which meets the requirements for being a DUV sensitive material (supplementary information S1). It is based on such high-quality $\mathrm{Si}_{3} \mathrm{~N}_{4}$ film that practical DUV photodetectors are expected to be demonstrated.

Taking the consideration of energy band calibration, metal platinum and indium are deposited on $\mathrm{Si}_{3} \mathrm{~N}_{4}$ and $\mathrm{Si}$, respectively, as the positive and negative electrodes. The vertical device structure is shown in the inset of Fig. 2. The 20 $\mathrm{nm}$ thin platinum layer is designed to be used as a translucent electrode, which not only guarantees a transmittance of more than $60 \%$ in the full band, but also has an excellent conductivity (S2). Correspondingly, the I-V characteristics of the photodetector in dark and $185 \mathrm{~nm}$ illumination are plotted in Fig. 2. The device exhibits an ultra-high switching ratio of more than $10^{3}$ and an open-circuit voltage of $0.41 \mathrm{~V}$, which ensures the practicality for detecting [17]. It can be seen from the figure that the dark current does not show obvious rectification characteristics, which is due to the huge resistance of $\mathrm{Si}_{3} \mathrm{~N}_{4}$ in dark condition [25], that is, the resistance of $\mathrm{Si}_{3} \mathrm{~N}_{4}$ has a greater influence on dark current than the heterojunction in this device. The current between metal and semiconductor is larger than the dark current over one order of magnitude at the same voltages 


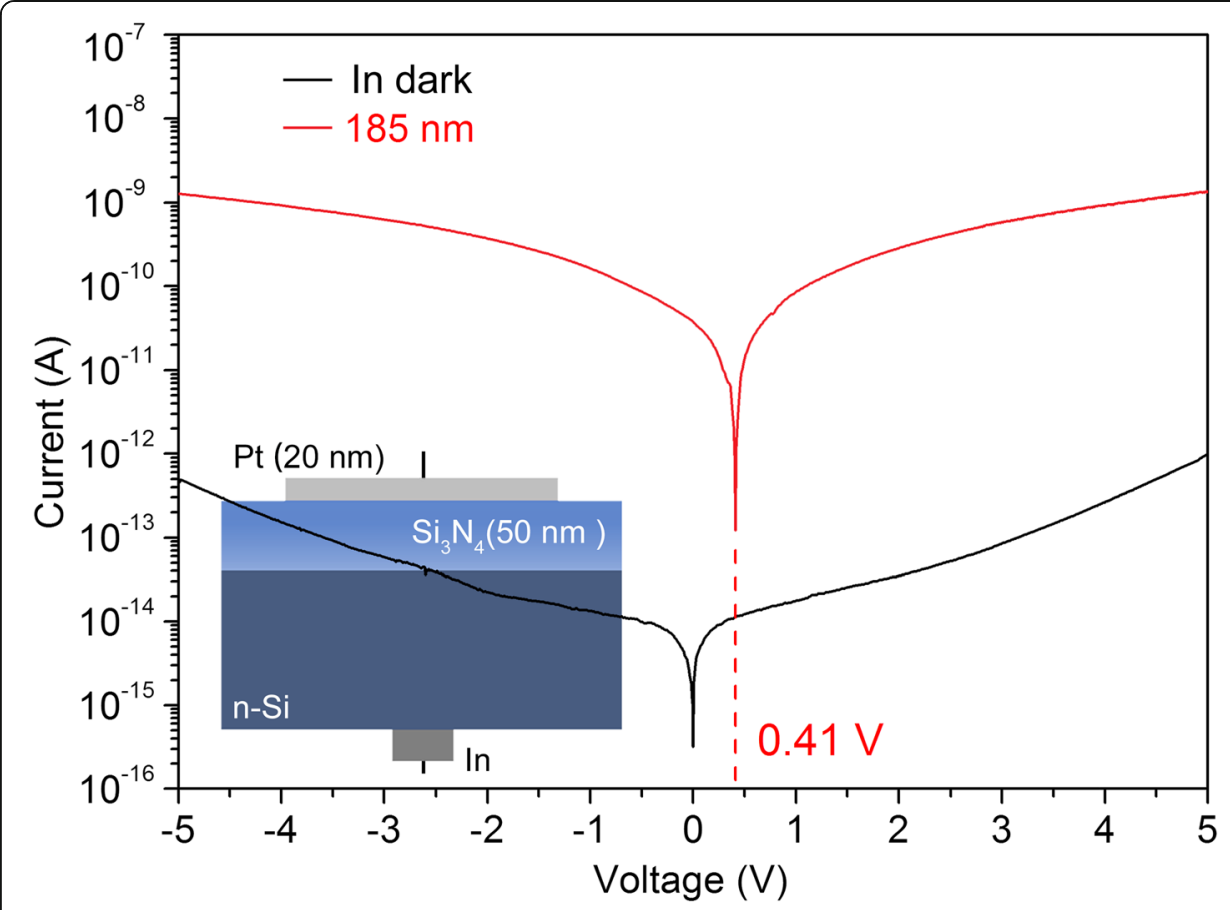

Fig. 2 Dark current and photocurrent of the detector. I-V characteristics of the fabricated $\mathrm{Si}_{3} \mathrm{~N}_{4} / \mathrm{n}-\mathrm{Si}$ photodetector under the dark and $185 \mathrm{~nm}$ illumination of $295.4 \mu \mathrm{W} / \mathrm{cm}^{2}$. The testing step of voltage is 0.01 $\mathrm{V}$. Inset is the schematic of the detector

(shown in S3), implying the metal-semiconductor junction is not the main component of built-in electric fields.

In order to verify the authenticity of the photogenerated voltage, a switch cycle test of the detector at $0 \mathrm{~V}$ bias is conducted, as shown in Fig. 3a. The photocurrent rises and falls as the light turned on and off at the $0 \mathrm{~V}$ bias voltage, indicating that the device is indeed a working photovoltaic detector, realizing self-driven DUV detection. Besides, the device also displays good stability in cycle test. It maintains similar performance during the illumination continuous switching on and off. From a single switch process (Fig. 3b), the difference in the speed of photocurrent rising and falling is observed. The rise time is larger than the fall time, and the rising photocurrent is composed of two parts, fast and slow response. The phenomenon originates from trap defects in the material and instability of the light source [26, 27]. Incident light excites the electrons in the valence band of $\mathrm{Si}_{3} \mathrm{~N}_{4}$ to the conduction band and generates free carriers. It takes a long time to reach equilibrium after being captured and then released by trap defects, causing the slow response [28]. In addition, limited by the experimental conditions, the $185 \mathrm{~nm}$ light slowly increases to the maximum intensity after turned on, resulting in a slower speed of photocurrent rising than falling. Using a laser as light source can eliminate the interference in the cycle test [10]. Temporal response characteristics of the detector are further characterized to explore the fastest speed (S5). The switch of the detector under the laser only takes $38 \mu \mathrm{s}$. We take view that the variation in response speed under two kinds of light sources, is due to the different switching speed of light source and also trap defects 

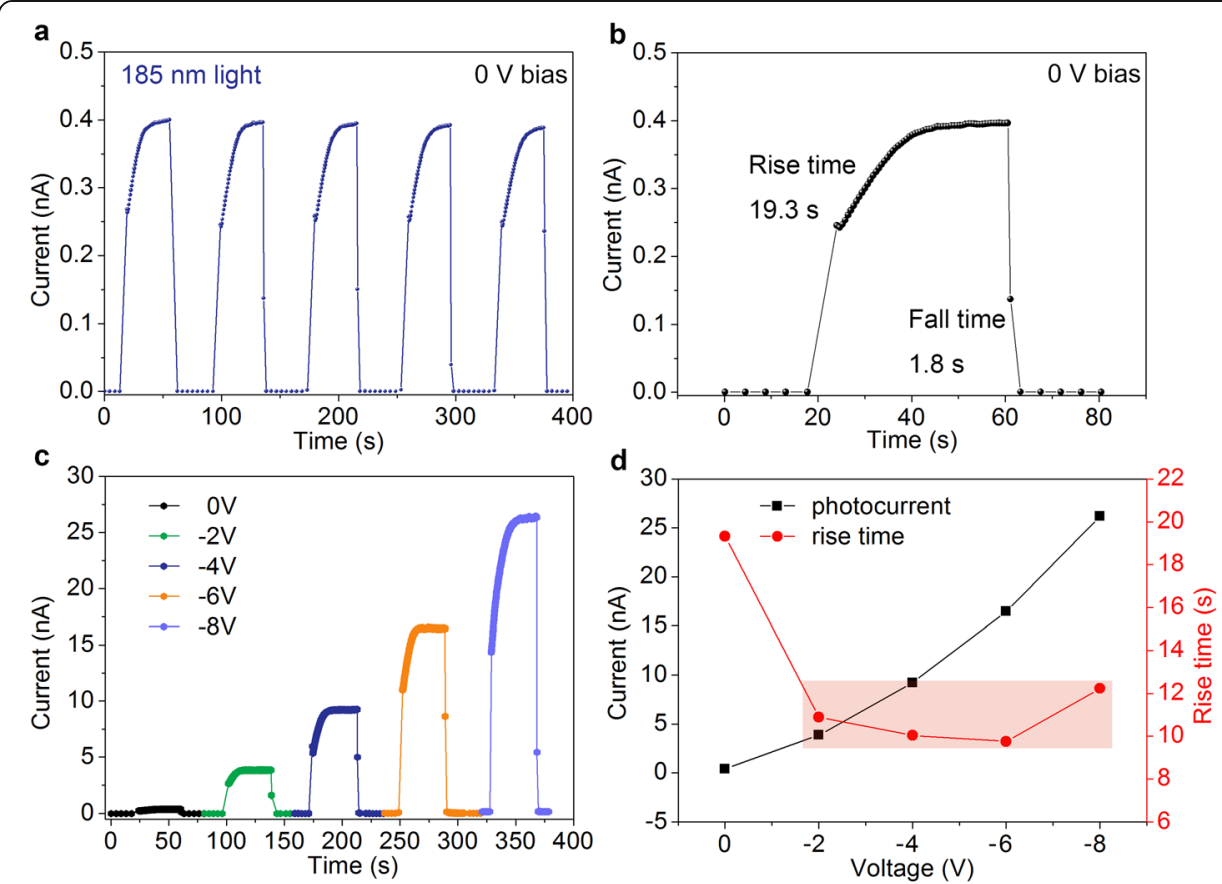

Fig. 3 Time-dependent response of the detector at a series of bias voltage. a Multi-cycle time-dependent photocurrent of the detector at $0 \mathrm{~V}$ bias, under $185 \mathrm{~nm}$ illumination of $295.4 \mu \mathrm{W} / \mathrm{cm}^{2}$. The current has been taken as an absolute value, same as below. $\mathbf{b}$ Single time-dependent photocurrent at $0 \mathrm{~V}$ bias. The rise time and fall time are 19.3 and $1.8 \mathrm{~s}$, respectively. Here, the range from $I_{\min }$ to $90 \%$ of $I_{\max }$ is defined as rise time, and the range from $I_{\max }$ to $10 \%$ of $I_{\max }$ is defined as fall time. c Time-dependent photocurrent at a series of bias voltage under the fixed $185 \mathrm{~nm}$ light power density of $295.4 \mu \mathrm{W} / \mathrm{cm}^{2}$. $\mathbf{d}$ Dependence of photocurrent and rise time on bias voltage. Red zone indicates the range of rise time, under the bias voltage from $-2 \mathrm{~V}$ to $-8 \mathrm{~V}$

in $\mathrm{Si}_{3} \mathrm{~N}_{4}$. In temporal response test, the defects are not excited, leading to a short time of rising photocurrent.

We explored the photoresponse of this detector at different bias voltages, as shown in Fig. 3c. The photocurrent rises super-linearly as the bias voltage increases, which is consistent with the typical volt-ampere characteristics. Unlimited increase of bias will cause detector breakdown [29]. The response speed is relatively slower at $0 \mathrm{~V}$, but fluctuates within an interval (around $10 \mathrm{~s}$ ) under other bias. Because the bias voltage accelerates the carriers drift and sweep them out of the depletion region to contribute to photocurrent [27]. It also shows that the switching speed of the detector saturates at a small bias voltage.

Dependence of the detector on light intensity and temperature is given in Fig. 4. With the enhancement of illumination, the photocurrent and the open-circuit voltage first increase rapidly, and then tend to saturate. Increased incident photons excite more electron-hole pairs, which contribute to improved photocurrent and built-in electric field. However, as the light intensity keeps increasing, the absorption of photons by the $\mathrm{Si}_{3} \mathrm{~N}_{4}$ film is saturated, and it cannot generate more photo-generated carriers, which leads to saturation of the current and open-circuit voltage, meanwhile making the responsivity (R) and external quantum efficiency (EQE) decrease accordingly. The definition of $R$ and EQE follows the reported work [30]. The responsivity formula is $R=$ $I_{\text {photo }} /\left(A \cdot P_{\text {inc }}\right)$, where $I_{\text {photo }}$ is the photocurrent, A the photoactive area, and $P_{\text {inc }}$ the 

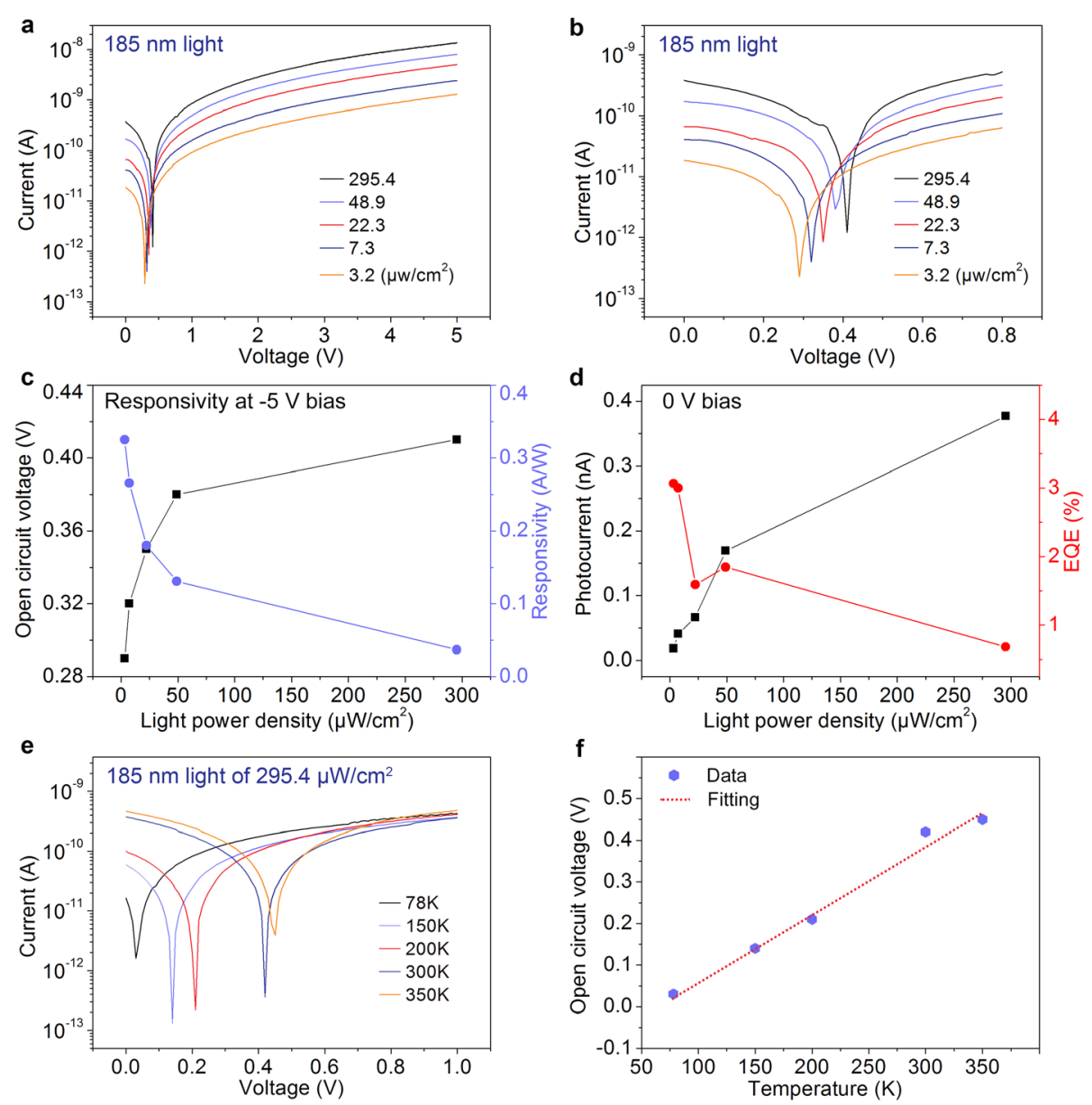

Fig. 4 Dependence of the $\mathrm{Si}_{3} \mathrm{~N}_{4} / \mathrm{n}$-Si detector on light intensity and temperature. a I-V characteristics of the $\mathrm{Si}_{3} \mathrm{~N}_{4} / \mathrm{n}$-Si photodetector with light power density from 3.2 to $295.4 \mu \mathrm{w} / \mathrm{cm}^{2}$. b I-V characteristics from Fig. $5 \mathrm{a}$ with extended axis ( 0 to $0.8 \mathrm{~V}$ ) to clearly show the open-circuit voltage. c Dependence of the opencircuit voltage and responsivity versus light intensity. Open-circuit voltage is extracted at $0 \mathrm{~V}$ bias, and responsivity is extracted at $-5 \mathrm{~V}$ bias. $\mathbf{d}$ Dependence of photocurrent and external quantum efficiency versus light intensity. e I- $\mathrm{V}$ characteristics of the $\mathrm{Si}_{3} \mathrm{~N}_{4} / \mathrm{n}$-Si photodetector with varying temperature from 78 $\mathrm{K}$ to $350 \mathrm{~K}$. $\mathbf{f}$ Linear dependence of the open-circuit voltage on temperature

incident light power. The calculation of EQE can be expressed by EQE $=\mathrm{hcR} / \mathrm{q} \lambda$, where $\mathrm{h}$ is Planck's constant, $\mathrm{c}$ the speed of light, $\mathrm{q}$ the electron charge, and $\lambda$ the incident wavelength. The detector exhibits a good responsivity of $0.325 \mathrm{~A} / \mathrm{W}$ and an extremely high EQE of $218 \%$, under an illumination intensity of $3.2 \mu \mathrm{W} / \mathrm{cm}^{2}$ and a bias voltage of $-5 \mathrm{~V}$. However, EQE decreased to $3.07 \%$ under $0 \mathrm{~V}$ bias, indicating that the external electric field has a significant effect on suppressing carrier recombination. In this work, the $\mathrm{Si}_{3} \mathrm{~N}_{4}$ film is only $50 \mathrm{~nm}$, and its ability to absorb light is not strong enough. We speculate that a suitable thickness of $\mathrm{Si}_{3} \mathrm{~N}_{4}$ film can optimize the detector's linear response interval versus light intensity.

From $78 \mathrm{~K}$ (liquid nitrogen temperature) to $350 \mathrm{~K}$, the I-V characteristics of the device are characterized. The open-circuit voltage decreases linearly with temperature, shown in Fig. 4f, which is due to the effect of temperature on carrier diffusion. The photogenerated voltage depends on the built-in electric field, which relies on the 
contact potential difference, and it can be described as $V_{D}=\frac{k_{0} T}{q}\left\{\ln \frac{N_{A} N_{D}}{n_{i}^{2}}\right\} . V_{D}$ is the contact potential difference, $\mathrm{K}_{0}$ the Boltzmann constant, $\mathrm{T}$ the temperature, $\mathrm{q}$ the electron charge, $\mathrm{N}_{\mathrm{A}}$ the acceptor concentration, $\mathrm{N}_{\mathrm{D}}$ the donor concentration, and $\mathrm{n}_{\mathrm{i}}$ the intrinsic carrier concentration. With other parameters fixed, $V_{D}$ varies linearly with $T$, which is consistent with the experimental fitting results.

Based on the analysis of the $\mathrm{Si}_{3} \mathrm{~N}_{4} / \mathrm{Si}$ heterojunction, $\mathrm{n}-\mathrm{Si}$ and $\mathrm{Si}_{3} \mathrm{~N}_{4}$ theoretically form a larger contact potential difference compared with $\mathrm{p}-\mathrm{Si}$, thereby providing a higher photo-generated voltage $[19,31]$. The band diagram and experimental results can be seen in S6. They are qualitatively consistent with each other, and the deviation of values is attributed to the interface states and shifting Fermi level of $\mathrm{Si}_{3} \mathrm{~N}_{4}$ from the intrinsic position [3, 32].

The detector's DUV selectivity is demonstrated by spectral response test (Fig. 5). It cuts off obviously in the long-wave UV region (>260 nm), which cannot be achieved by current commercial silicon photodiodes, complementing the lack of detectors specially used for DUV. Therefore, it will be not necessary for $\mathrm{Si}_{3} \mathrm{~N}_{4} / \mathrm{Si}$ detectors to add filtering apparatus or signal separation equipment. Study for improving the suppression ratio is ongoing.

In two methods, LPCVD method obtains a $\mathrm{Si}_{3} \mathrm{~N}_{4}$ layer through nitriding silicon wafer via $\mathrm{N}_{2}$, and ICPCVD method deposits $\mathrm{Si}_{3} \mathrm{~N}_{4}$ onto the silicon surface by reacting $\mathrm{NH}_{3}$ with $\mathrm{SiH}_{4}$. The two types of $\mathrm{Si}_{3} \mathrm{~N}_{4} / \mathrm{Si}$ composite detectors do not differ much in characterizations, except for the response speed. The ICPCVD-Si ${ }_{3} \mathrm{~N}_{4} / \mathrm{Si}$ detector reached the

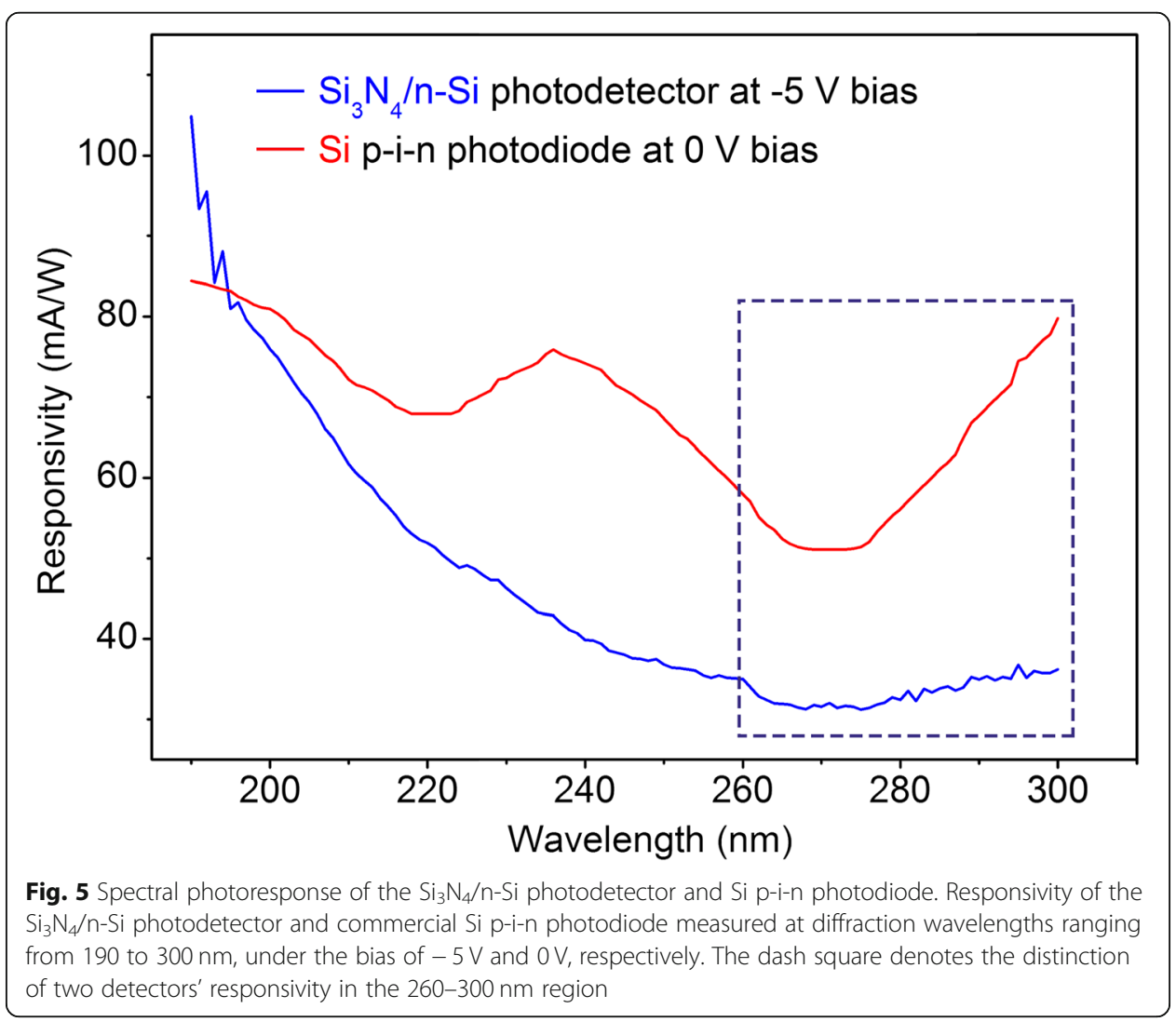



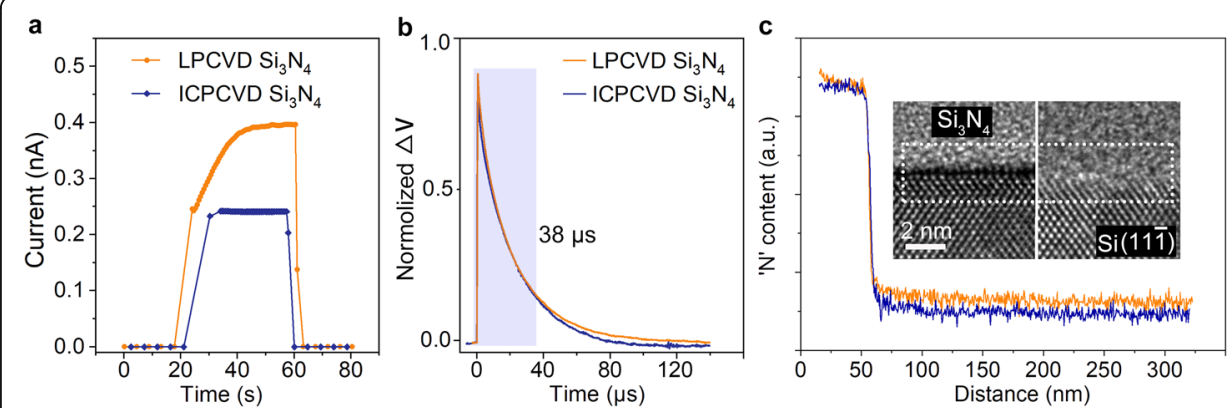

Fig. 6 Time-dependent and temporal photoresponse of two types of detectors, and analysis of the interfaces. a Time-dependent photoresponse of two types of $\mathrm{Si}_{3} \mathrm{~N}_{4} / \mathrm{n}$-Si photodetectors, under the same illumination intensity. b Single temporal photovoltaic response of the two detectors under $193 \mathrm{~nm}$ pulsed laser. c Nitrogen element line scan of the two interfaces between $\mathrm{Si}_{3} \mathrm{~N}_{4}$ and $\mathrm{Si}$, and the scanning step is 0.5 $\mathrm{nm}$. The inset is HRTEM image of the two interfaces between $\mathrm{Si}_{3} \mathrm{~N}_{4}$ and $\mathrm{Si}$. The left is LPCVD-Si $\mathrm{N}_{4}$, and the right is ICPCVD-Si ${ }_{3} \mathrm{~N}_{4}$

saturation state more quickly in the time-dependent response test, as shown in Fig. 6 a. However, further temporal response indicates the switching speeds tend to be similar under the ultrafast $193 \mathrm{~nm}$ pulsed laser. The element distribution and lattice at the interface are analyzed (Fig. 6c) to explore the underlying mechanism. The nitrogen element line scan perpendicular to the interface direction shows that both the two types of $\mathrm{Si}_{3} \mathrm{~N}_{4}$ cut off well at the interface and do not diffuse into silicon, indicating the response speed difference is not due to the non-uniformity of built-in electric fields. HRTEM shows that the interface of LPCVD- $\mathrm{Si}_{3} \mathrm{~N}_{4}$ is flatter, but the shaded area indicates defects possibly. In this work, we take the point that in ICPCVD method, the hydrogen element in the growing sources $\left(\mathrm{NH}_{3}\right.$ and $\left.\mathrm{SiH}_{4}\right)$ has the effect of passivating trap state defects [33, 34], making the photo-generated carriers saturate faster, which shortens the slow response process. This is consistent with the analysis of switching speed mentioned above in Fig. 3.

\section{Conclusions}

In this work, compact and flat $\mathrm{Si}_{3} \mathrm{~N}_{4}$ film is prepared by the CVD methods, and integrated with $\mathrm{Si}$ to fabricate DUV detectors. Its temporal switching takes only $38 \mu$ s. Compared with commercial silicon $\mathrm{p}-\mathrm{i}-\mathrm{n}$ photodiodes, the cut-off response to long-wave UV light of $\mathrm{Si}_{3} \mathrm{~N}_{4} / \mathrm{Si}$ detectors indicates the designed selectivity for DUV, rather than a broad band. This detector exhibits a good responsivity of 0.325 $\mathrm{A} / \mathrm{W}$ and a high EQE of $218 \%$ at $-5 \mathrm{~V}$ bias. A range of characterizations including cycling switching test, energy band calibration, temperature and light intensity dependence tests all imply a reliable and efficient device. The distinction of response speed between the LPCVD- $\mathrm{Si}_{3} \mathrm{~N}_{4} / \mathrm{Si}$ and ICPCVD- $\mathrm{Si}_{3} \mathrm{~N}_{4} / \mathrm{Si}$ detectors is also explained by analyzing the interface defects, which provides a reference for the further preparation of other high-performance detectors. In general, this research lays a foundation for the development of applicable DUV imaging photodetectors and provides the theoretical basis. 


\title{
Methods
}

$\mathrm{Si}_{3} \mathrm{~N}_{4}$ film growth: LPCVD method took nitrogen as $\mathrm{N}$ growth source, which reacted with silicon at $1200{ }^{\circ} \mathrm{C}$ to form amorphous $\mathrm{Si}_{3} \mathrm{~N}_{4}$. The LPCVD- $\mathrm{Si}_{3} \mathrm{~N}_{4}$ film was purchased from Nanjing MKNANO. Tech. Co., Ltd. In ICPCVD method, $\mathrm{NH}_{3}$ and $\mathrm{SiH}_{4}$ reacted at $300^{\circ} \mathrm{C}$ forming $\mathrm{Si}_{3} \mathrm{~N}_{4}$ film, and the flow ratio between $\mathrm{NH}_{3}$ and $\mathrm{SiH}_{4}$ was 14: 10.5. The ICPCVD deposition system is a Plasma lab System 100 ICP180 from Oxford Instruments Plasma Technologies.

Device fabrication: a round Platinum electrode with the radius of $200 \mu \mathrm{m}$ was deposited on $\mathrm{Si}_{3} \mathrm{~N}_{4}$ surface by ion sputtering. The thickness of Platium layer is $20 \mathrm{~nm}$. Then, thermally fused indium was plated at the side of $\mathrm{Si}$ as the back electrode.

Material characterization: The AFM image, cross-sectional SEM morphology, EDS and chemical composition mapping were characterized by CSPM 5500 and ZEISSAURIGA Focused Ion Beam etching system. The XPS pattern were collected by an X-ray photoelectron spectroscope (Thermo Fisher ESCALAB 250Xi). The FTIR spectrum and transmittance spectra was conducted by Fourier infrared spectrometer (Shimadzu IRAffinity-1S) and UV-VIS spectrophotometer (Shimadzu UV-3600). The nitrogen element line-scan and HRTEM test was performed by Tecnai G2 F30 of FEI $(300 \mathrm{kV})$.

Device measurements: The $185 \mathrm{~nm}$ monochromatic light was obtained from the spectral line of a quartz-packaged low-pressure mercury lamp through an optical filter, and the light power density was measured by the VXUV20A photodetector from Opto Diode Corp. The I-V characteristics of the device were measured by using Keithley 4200 source meter, equipped with a temperature-adjustable platform and a vacuum chamber. The temporal responses were measured by a $6 \mathrm{G}$ oscilloscope, KEYSIGHT DSOS604A, whereas the $193 \mathrm{~nm}$ pulsed light was from GAMLASEREX5/250 mini excimer laser. The DUV spectral-response test system used Shimadzu UV-2600 as continuous adjustable light source, with KEITHLEY 2636b as SourceMeter.

\section{Supplementary information}

Supplementary information accompanies this paper at https://doi.org/10.1186/s43074-020-00014-w.

Additional file 1. Includes: Section 1. The plot of $(a h v)^{2}$ as a function of incident photon energy (hv) into $\mathrm{Si}_{3} \mathrm{~N}_{4}$; Section 2. Characterizations of platium electrodes; Section 3. I-V characteristics of the metal-semiconductor junctions; Section 4. Schematic diagram of transient response test; Section 5. Temporal response of the detector;

Section 6. I-V characteristics of the $\mathrm{Si}_{3} \mathrm{~N}_{4} / \mathrm{n}-\mathrm{Si}$ and $\mathrm{Si}_{3} \mathrm{~N}_{4} / \mathrm{p}-\mathrm{Si}$ detectors, and the energy band diagram.

\begin{abstract}
Abbreviations
DUV: Deep ultraviolet; LPCVD: Low-pressure chemical vapor deposition; ICPCVD: Inductively coupled plasma chemical vapor deposition; SEM: Scanning electron microscope; HRTEM: High-resolution transmission electron microscope; AFM: Atomic force microscope; EDS: Energy dispersive spectroscopy; XPS: X-ray spectroscopy; FTIR: Fourier transform infrared; R: Responsivity; EQE: External quantum efficiency
\end{abstract}

Acknowledgements

Not applicable.

Authors' contributions

W.Z. and F.H. conceived and directed this work. Y.L. performed the experiments. Y.L. and W.Z. discussed the results. Y.L. drew the pictures and wrote the manuscript. The author(s) read and approved the final manuscript. 
Availability of data and materials

All data generated and analyzed during this study are included in this published article and its supplementary information files.

\section{Competing interests}

The authors declare no competing interests.

Received: 8 April 2020 Accepted: 29 May 2020

Published online: 08 June 2020

\section{References}

1. Assefa S, Xia F, Vlasov YA. Reinventing germanium avalanche photodetector for nanophotonic on-chip optical interconnects. Nature. 2010;464:80-4

2. Monroy E, Omnès F, Calle F. Wide-bandgap semiconductor ultraviolet photodetectors. Semicond Sci Technol. 2003; 18(4):R33-51.

3. Zhang D, Zheng W, Lin R, Li Y, Huang F. Ultrahigh EQE (15\%) solar-blind UV photovoltaic detector with organicinorganic Heterojunction via dual built-in fields enhanced photogenerated carrier separation efficiency mechanism. Adv Funct Mater. 2019;29(26):1900935

4. Chamberlain SG. Photosensitivity and scanning of silicon image detector arrays. IEEE J Solid State Circuits. 1969:4(6):333-42

5. Chamberlain SG, Lee JPY. A novel wide dynamic range silicon photodetector and linear imaging array. IEEE J Solid State Circuits. 1984:19(1):41-8.

6. Zheng W, Huang F, Zheng R, Wu H. Low-dimensional structure vacuum-ultraviolet-sensitive $(\lambda<200$ nm) Photodetector with fast-response speed based on high-quality AIN micro/nanowire. Adv Mater. 2015;27(26):3921-7.

7. Yin J, Tan Z, Hong H, Wu J, Yuan H, Liu Y, et al. Ultrafast and highly sensitive infrared photodetectors based on twodimensional oxyselenide crystals. Nat Commun. 2018;9(1):3311.

8. Liu H, Meng J, Zhang X, Chen Y, Yin Z, Wang D, et al. High-performance deep ultraviolet photodetectors based on fewlayer hexagonal boron nitride. Nanoscale. 2018;10(12):5559-65.

9. Zhou AF, Aldalbahi A, Feng P. Vertical metal-semiconductor-metal deep UV photodetectors based on hexagonal boron nitride nanosheets prepared by laser plasma deposition. Opt Mater Express. 2016;6(10):3286-92.

10. Zheng W, Lin R, Ran J, Zhang Z, Ji X, Huang F. Vacuum-ultraviolet photovoltaic detector. ACS Nano. 2018;12(1): 425-31.

11. Qin Y, Li L, Zhao X, Tompa GS, Dong H, Jian G, et al. Metal-semiconductor-metal $\varepsilon$-Ga2O3 solar-blind Photodetectors with a record-high responsivity rejection ratio and their gain mechanism. ACS Photonics. 2020; 7(3):812-20.

12. Sun H, Li K-H, Castanedo CGT, Okur S, Tompa GS, Salagaj T, et al. HCl flow-induced phase change of a-, $\beta$-, and $\varepsilon-G a 2 O 3$ films grown by MOCVD. Cryst Growth Des. 2018;18(4):2370-6.

13. Afanasev W, Bassler M. Pensl G, Schulz M. Intrinsic SiC/SiO2 Interface States. Physica Status Solidi (a). 1997;162(1): 321-37.

14. Watanabe K, Taniguchi T, Kanda H. Direct-bandgap properties and evidence for ultraviolet lasing of hexagonal boron nitride single crystal. Nat Mater. 2004;3(6):404-9.

15. Yang W, Chen G, Shi Z, Liu C-C, Zhang L, Xie G, et al. Epitaxial growth of single-domain graphene on hexagonal boron nitride. Nat Mater. 2013;12:792.

16. Wei T, Islam SM, Jahn U, Yan J, Lee K, Bharadwaj S, et al. GaN/AIN quantum-disk nanorod $280 \mathrm{~nm}$ deep ultraviolet light emitting diodes by molecular beam epitaxy. Opt Lett. 2020:45(1):121-4.

17. Michel J, Liu J, Kimerling LC. High-performance Ge-on-Si photodetectors. Nat Photonics. 2010;4:527.

18. Shao Z, Chen Y, Chen H, Zhang Y, Zhang F, Jian J, et al. Ultra-low temperature silicon nitride photonic integration platform. Opt Express. 2016;24(3):1865-72.

19. Weinberg ZA, Pollak RA. Hole conduction and valence-band structure of Si3N4 films on Si. Appl Phys Lett. 1975;27(4): 254-5.

20. Bauer J. Optical properties, band gap, and surface roughness of Si3N4. Physica status solidi (a). 1977;39(2):4118 .

21. Chang H, Chen Z, Li W, Yan J, Hou R, Yang S, et al. Graphene-assisted quasi-van der Waals epitaxy of AlN film for ultraviolet light emitting diodes on nano-patterned sapphire substrate. Appl Phys Lett. 2019;114(9):091107.

22. Li Y, Zhang D, Lin R, Zhang Z, Zheng W, Huang F. Graphene interdigital electrodes for improving sensitivity in a Ga2O3: Zn deep-ultraviolet photoconductive detector. ACS Appl Mater Interfaces. 2019;11(1):1013-20.

23. Bertóti I, Varsányi G, Mink G, Székely T, Vaivads J, Millers T, et al. XPS characterization of ultrafine Si3N4 powders. Surf Interface Anal. 1988;12(10):527-30

24. Wada N, Solin SA, Wong J, Prochazka S. Raman and IR absorption spectroscopic studies on a, $\beta$, and amorphous Si3N4. J Non-Cryst Solids. 1981:43(1):7-15.

25. Kumar M, Roul B, Bhat TN, Rajpalke MK, Kalghatgi AT, Krupanidhi SB. Carrier-transport studies of III-nitride/Si3N4/Si isotype heterojunctions. Physica status solidi (a). 2012;209(5):994-7.

26. Oh S, Kim C-K, Kim J. High Responsivity $\beta-G a 2 O 3$ metal-semiconductor-metal solar-blind photodetectors with ultraviolet transparent graphene electrodes. ACS Photonics. 2018;5(3):1123-8.

27. Kong W, Wu G, Wang K, Zhan T, Zou Y, Wang D, et al. Graphene- $\beta-G a 2 O 3$ heterojunction for highly sensitive deep UV photodetector application. Adv Mater. 2016;28(48):10725-31.

28. Guo DY, Wu ZP, An YH, Guo XC, Chu XL, Sun CL, et al. Oxygen vacancy tuned Ohmic-Schottky conversion for enhanced performance in $\beta$-Ga2O3 solar-blind ultraviolet photodetectors. Appl Phys Lett. 2014;105(2):023507-11.

29. Dong H, Long S, Sun H, Zhao X, He Q, Qin Y, et al. Fast switching beta-Ga2O3 power MOSFET with a trench-gate structure. IEEE Electron Device Lett. 2019;40(9):1385-8.

30. Koppens FHL, Mueller T, Avouris P, Ferrari A, Vitiello MS, Polini M. Photodetectors based on graphene, other twodimensional materials and hybrid systems. Nat Nanotechnol. 2014;9(10):780-93. 
31. Gritsenko VA, Morokov YN, Novikov YN. Electronic structure of amorphous Si3N4: experiment and numerical simulation. Appl Surf Sci. 1997;113-114:417-21.

32. Sun H, Torres Castanedo CG, Liu K, Li K-H, Guo W, Lin R, et al. Valence and conduction band offsets of $\beta$-Ga2O3/AlN heterojunction. Appl Phys Lett. 2017;111(16):162105.

33. Qin Y, Sun H, Long S, Tompa GS, Salagaj T, Dong H, et al. High-performance metal-organic chemical vapor deposition grown \$lvarepsilon\$-Ga2O3 solar-blind photodetector with asymmetric Schottky electrodes. IEEE Electron Device Lett. 2019;40(9):1475-8.

34. Li C-T, Hsieh F, Wang L. Performance improvement of p-type silicon solar cells with thin silicon films deposited by low pressure chemical vapor deposition method. Sol Energy. 2013;88:104-9.

\section{Publisher's Note}

Springer Nature remains neutral with regard to jurisdictional claims in published maps and institutional affiliations.

Submit your manuscript to a SpringerOpen ${ }^{\odot}$ journal and benefit from:

- Convenient online submission

- Rigorous peer review

- Open access: articles freely available online

- High visibility within the field

- Retaining the copyright to your article

Submit your next manuscript at $\boldsymbol{\nabla}$ springeropen.com 